\title{
Medida de Segurança: a violação do direito à saúde a partir do conceito de periculosidade
}

\author{
Safety Measure: the violation of the right to health from the concept of dangerousness
}

\section{Valéria Rondon Rossi ${ }^{1}$}

Resumo: A relação dos fenômenos da loucura e criminalidade foi um ponto estratégico para a constituição da medicina mental - psiquiatria - e para a constituição de instituições de controle, punição e regeneração. O objetivo do trabalho é questionar se esse modelo de intervenção psiquiátrico-penal garante ao louco infrator o respeito ao seu direito à saúde $A$ hipótese é que a periculosidade é um conceito não científico, balizado por conceitos morais que identificam loucura como manifestação de perigo. A pesquisa é descritiva de caráter qualitativo, baseada em revisão bibliográfica e análise de dados coletados pela pesquisa „A Custódia e o Tratamento Psiquiátrico no Brasil: censo 2011". Conclui-se que a medida se justifica por dispositivo frágil do ponto de vista psiquiátrico e penal - a periculosidade do indivíduo -, que não apresenta elementos objetivos de identificação e quantificação, indicando tendência à adoção de modelo punitivo voltado à defesa social em detrimento da ressocialização do louco infrator.

Palavras-chave: Loucura, Periculosidade, Medida de Segurança, Direito à saúde.

Resumen: La relación entre los fenómenos de la locura y del crimen fue un punto estratégico para la constitución de la medicina mental y para la formación de las instituciones de control, castigo y regeneración. El propósito de este artículo es cuestionar si este modelo de intervención psiquiátrica-penal garantiza al loco infractor el respeto a su derecho a la salud, o si es un mecanismo para garantizar el orden social a partir de la clasificación de los individuos considerados peligrosos. La hipóthesis del trabajo es que la peligrosidad es un concepto no científico, marcado por conceptos morales que identifican a la locura como una manifestación de peligro en sí misma. Este estudio es de carácter descriptivo y cualitativo, basado en la revisión bibliográfica y análisis de los datos recogidos por la investigación „La custodia y el tratamiento psiquiátrico en Brasil: Censo 2011". Se puede concluir que la medida de seguridad se justifica por un dispositivo frágil del punto de vista psiquiátrico y penal - la peligrosidad del individuo - que no es basada en una identificación o cuantificación de factores objetivos, lo que indica una tendencia a adoptar un modelo punitivo centrado en la defensa social a expensas de la rehabilitación del loco delincuente.

Palabras-Ilave: Locura, Peligrosidad, Medida de Seguridad, Derecho a la salud.

\begin{abstract}
The relationship between the phenomena of insanity and criminality was a strategic point for the constitution of mental medicine - psychiatry - and for the establishment of institutions of control, punishment and regeneration. The purpose of this paper is to question whether this model of criminal-psychiatric intervention ensures to the insane criminal offender the respect to his/her right to health, or if it is a mechanism for ensuring social order by isolating individuals considered dangerous. The paper's hypothesis is that dangerousness

\footnotetext{
${ }^{1}$ Psicóloga, Especialista em Direito Sanitário pela FIOCRUZ - Brasília. Especialista em Gestão em Saúde pela UNESP. Especialista na Docência na Educação Superior. Psicóloga perita complementar na Gerência de Saúde Ocupacional e Segurança do Trabalhador - GESOST da Coordenação de Saúde Ocupacional - COSAÚDE / SEE/DF. Professora de Psicologia da Secretaria de Estado de Educação do Distrito Federal. Brasília, Brasil. E-mail: vrrossi@gmail.com.
} 
is a nonscientific concept, marked by moral concepts that identify madness as a manifestation of danger in itself. It is a descriptive and qualitative research, based on literature review and analysis of data collected by the survey "The Custody and Psychiatric Treatment in Brazil: 2011 Census". It is concluded that the security measure is justified by a fragile psychiatric and criminal concept - the dangerousness of the individual - which does not provide identification and quantification purposes elements, indicating a tendency to adopt a punitive model focused on social defense at the expense of rehabilitation of the insane criminal offender.

Keywords: Insanity, Dangerousness, Safety Measure, Right to health.

\section{Introdução}

Desde o início das civilizações a loucura despertou, alternadamente, curiosidade e terror em todas as esferas que compõem a sociedade. Ora considerada sinal de divindade ou inspiração artística e intelectual, ora relegada ao desprezo social e descrita como fonte de desordem e perigo, as percepções acerca da loucura sofreram mudanças e ressignificações ao longo da história (1).

A relação estabelecida entre o fenômeno da loucura e a criminalidade foi um ponto estratégico para a constituição da medicina mental - psiquiatria - e, por consequência, para a constituição de instituições de controle, punição e regeneração (2) (3). Constata-se que a criação do manicômio foi a resposta social à loucura (4) (5). E o manicômio judiciário o lugar destinado às pessoas perigosas que deveriam ficar excluídas da sociedade, o indivíduo portador de transtorno mental autor de algum delito, ou seja, o louco infrator.

Os loucos infratores são considerados inimputáveis no Brasil, o que significa que não são indivíduos a quem se possa aplicar uma pena, pois não são reputados responsáveis por seus atos. O objetivo do presente artigo é questionar se esse modelo de intervenção psiquiátrico-penal garante ao louco infrator o respeito ao seu direito à saúde ou se é, por outro lado, um mecanismo de garantia da ordem social a partir da apartação de sujeitos considerados perigosos. A hipótese do trabalho é de que a periculosidade é um conceito não-científico, balizado por conceitos morais que identificam a loucura como uma manifestação de perigo em si e permitem a apartação indefinida dos loucos infratores, não uma avaliação sobre tratamento e saúde.

A construção desse estudo apresenta-se uma discussão sobre os conceitos de inimputabilidade, periculosidade e medida de segurança para a doutrina jurídica e para o direito penal. Por fim, o arcabouço teórico é utilizado para subsidiar a análise dos dados apresentados na pesquisa "A Custódia e o Tratamento Psiquiátrico no Brasil: Censo 2011" 
Cad. Ibero-Amer. Dir. Sanit., Brasília, v.4, n.3, jul./set. 2015 ISSN 2358-1824

(6), com o objetivo de avaliar empiricamente de que forma o atual modelo de tratamento e punição imposto aos loucos infratores tem influenciado suas vidas no interior dos Estabelecimentos de Custódia e Tratamento Psiquiátrico (ECTPs), antigos manicômios judiciários. São avaliados, nesse ponto, aspectos relativos à entrada no sistema, à permanência, possibilidade de saída pela suspensão da medida - cessação de periculosidade - e observância aos direitos e garantias dos portadores de sofrimento mental.

\section{Metodologia}

Trata-se de pesquisa descritiva de caráter qualitativo, baseada especialmente em revisão bibliográfica e análise de dados coletados no trabalho „A Custódia e o Tratamento Psiquiátrico no Brasil: Censo 2011", realizado pela equipe da ONG Anis - Instituto de Bioética, Direitos Humanos e Gênero². Assim, o estudo reveste-se de caráter qualitativo e exploratório, pois se destina a investigar uma realidade pouco conhecida e debatida, a internação manicomial no Brasil. Uma das principais características da pesquisa exploratória é a flexibilidade no seu planejamento e a utilização do levantamento bibliográfico como principal fonte (7).

A revisão da literatura acerca do tema foi principalmente realizada mediante consulta à base de dados eletrônicos da Biblioteca Virtual em Saúde e Scielo, para a coleta dos dados necessários à execução da pesquisa. Os critérios de inclusão para seleção dos artigos foram: artigos nacionais, publicados no idioma português, no período de 2002 - após a Reforma Psiquiátrica ocorrida com a aprovação da Lei no 10.216/2001 (8) - a 2014, cuja abordagem tivesse referência direta com o tema.

A partir de ampla revisão bibliográfica e da leitura criteriosa dos artigos encontrados, a análise seguiu as perspectivas propostas por Minayo (9), por meio da análise temática, operacionalizada em três etapas: a pré-análise, a exploração do material e o tratamento dos resultados e interpretação.

\footnotetext{
${ }^{2}$ Esta pesquisa foi, até o momento, o primeiro e único esforço para realização de um levantamento sobre os manicômios judiciários no Brasil. Encomendado pelo Ministério da Justiça, „A Custódia e o Tratamento Psiquiátrico no Brasil - Censo 2011" foi coordenado pela antropóloga e professora da Universidade de Brasília (UnB), Debora Diniz.
} 


\section{Da Loucura Divina à Loucura Perigosa - o Processo de Psiquiatrização da Loucura}

A loucura nem sempre foi considerada um problema, uma condição existencial pejorativa ou negativa. Pelo contrário, houve tempos na história humana em que sinais de desrazão foram considerados manifestações de uma existência superior. Na Grécia antiga, por exemplo, acreditava-se que o ser delirante era um privilegiado, pois tinha a capacidade de se comunicar com as divindades, com o sagrado. Era prerrogativa de somente alguns terem acesso às verdades divinas (10).

Há evidências de que até o período que se convencionou chamar Idade Média, os loucos não eram submetidos a processos de reclusão, podiam andar livremente pelas cidades, circular entre as pessoas e viver de caridade pelas ruas. No Renascimento, a loucura passou por dois momentos, conforme Machado (11): em uma primeira fase, foi entendida como uma espécie de vocação, propensa às artes plásticas e às pinturas; na segunda, mais elaborada a partir de saberes filosóficos e literários, passou a ser compreendida como uma desmoralização do saber.

Silveira e Braga (12) demonstram nos seus estudos que "paulatinamente, a loucura vai se afastando do seu papel de portadora da verdade e vai se encaminhando em uma direção oposta", pois, segundo esses autores, "a loucura já não é mais porta-voz da verdade divina e em pouco tempo passará a ocupar o lugar de representante simbólico do mal". Dessa forma, a loucura que antes era tolerada ou mesmo admirada, passa a ser rejeitada e atribuída à desordem social. No século XVI, a visão da loucura passa a ser entendida como um processo de desrazão, como tudo aquilo que uma sociedade enxerga como sendo seu outro: a estranheza, a ameaça, a alteridade radical (10).

No decorrer do século XVII, as ideias de despossessão da razão e possessão demoníaca passaram coabitar os diagnósticos médicos, mas para diferentes indivíduos. Dechambre (13) afirma que os médicos "diante de manifestações dos insensatos e dementes" tinham duas possibilidades: „ora se orientavam pelo diagnóstico organicista, ora pelo metafísico, mas um excluía o outro". Concepções religiosas e biologizantes conflitavam: o indivíduo podia ser considerado insensato, por origens orgânicas; ou demente, porque possuído pelo demônio.

Os hospitais gerais e as Santas Casas já nessa época abrigavam todos aqueles considerados necessitados de internação, como os leprosos, as prostitutas, os loucos e até 
os criminosos. Goffman (14) define esses lugares como "instituição total", um local onde um grande número de indivíduos com situação semelhante, separados da sociedade mais ampla por considerável período de tempo levam uma vida fechada e formalmente administrada. Todavia, esses espaços ainda não tinham a conotação da medicalização, e, com isso, os loucos não passavam por tratamento médico específico.

É no século XVIII que o fenômeno da loucura, segundo Foucault (15), passa a ser definitivamente objeto do saber médico, passa a ter o status de alienação e o reconhecimento como doença mental, o que faz com que seja passível de tratamento e cura. Não é mais descrita como um domínio do divino ou do inexplicável, mas como domínio da ciência. Assim, o louco é o alienado, tendo essa expressão a mesma origem etimológica de alien, estrangeiro de fora do mundo e da realidade.

Ocorre, então, o marco inaugural da chamada medicina mental, o nascimento da psiquiatria como uma área especializada e responsável por ditar destino aos tidos como loucos e alienados. Surge o manicômio como instituição para abrigar o louco separadamente dos demais indivíduos desviantes. A perspectiva é, em tese, de saúde: nessa instituição a loucura seria tratada por médicos com vistas à cura, de acordo com a ordem fundada pelo médico francês Philippe Pinel, considerado o fundador da psiquiatria. O método criado por Pinel estabelecia a doença como problema de ordem moral e, assim, o método terapêutico para a loucura era denominado "tratamento moral", o qual era baseado em confinamentos, sangrias e purgativos, sendo esse o primeiro método terapêutico para a loucura na modernidade (16) (4) (15).

Foucault (5) afirma que a transformação do hospital psiquiátrico numa instituição medicalizada se deu a partir da ação sistemática e dominante da disciplina, da organização e esquadrinhamento médicos, sendo o momento em que a loucura transformou-se em questão social, passando a ser regulada e contida numa instituição. Não se tratava de um tratamento mais humano e, muito menos, de um reconhecimento positivo da loucura, mas de uma meticulosa operação na qual pela primeira vez há a união do pensamento médico com a prática do internamento (17).

A loucura firmou-se como verdade médica e a psiquiatria efetivando-se como „um imperativo de ordenação dos sujeitos", conforme afirma Amarante (18). A psiquiatria como saber científico, o psiquiatra como médico especialista e o manicômio como única instituição destinada ao tratamento terapêutico da doença mental perigosa (19). 


\section{Manicômio e Manicômio Judiciário - Lugar Social do Louco e do Louco Infrator}

As unidades hospitalares criadas para pessoas portadoras de transtornos mentais com o cunho segregacionista, começaram a funcionar no início do século XX, no Brasil, os espaços asilares para receber e tratar os ditos loucos criminosos, pessoas portadoras de transtornos mentais que cometeram delitos (20). A criação oficial dos manicômios judiciários ocorreu pelo Decreto oํ 1.132, de 22 de dezembro de 1903 (21). A criação de manicômios judiciários ou criminais visou garantir a separação entre loucos criminosos e criminosos comuns (22). A tônica de exclusão proporcionada pela instituição asilar estabelece a diferença entre loucos comuns e loucos criminosos.

O manicômio judiciário figura como uma instituição „prisão de caráter especial, prisão e manicômio ao mesmo tempo" (2), pretendendo corresponder aos interesses tanto da área de saúde como do âmbito jurídico. Nesse sentido, Barros-Brisset (13) explica que sendo unânime o entendimento de que a periculosidade era intrínseca à loucura, então, "o direito deveria apresentar um mecanismo especial para tratar o indivíduo perigoso, separando-o da sociedade até cessar a sua periculosidade, em nome da defesa social".

A partir do encontro da periculosidade social da loucura com o conceito de doença mental trazido pela medicina ocorreu "uma sobreposição entre punição e tratamento, uma quase identidade do gesto que pune e aquele que trata" (23).

\section{A Inimputabilidade, a Periculosidade e a Medida de Segurança no Código Penal}

$\mathrm{Na}$ opinião de Marques (24), a introdução formal do instituto das medidas de segurança foi a mais profunda modificação proposta pelo Código Penal de 1940 em relação ao sistema penal anterior, que definia que os loucos ou insanos que houvessem cometido crimes deveriam ser entregues às suas famílias ou, então, recolhidos e internados em casas especialmente destinadas a acolhê-los. As medidas de segurança foram sistematizadas no anteprojeto de código penal de Virgílio de Sá Pereira em 1927, "no qual se inaugurou o reconhecimento expresso à responsabilidade diminuída ou atenuada" (25). 
Mas, foi no Código de 1940 que 'as medidas de segurança vieram a consolidar-se [...] e generalizar-se como alternativa para aqueles que eram "criminosos natos e incidiam em conduta humana típica e antijurídica, mas que eram inimputáveis" (26).

Dessa forma, o indivíduo infrator somente será isento de pena e, assim, considerado inimputável para ser absolvido, de acordo com o Código Penal, se seu estado mental o tiver privado completamente da capacidade psicológica, ou seja, se o fator patológico tiver eliminado inteiramente tanto a sua função ou capacidade de entendimento como a de vontade em relação à sua conduta criminosa. O critério adotado é, portanto, biopsicológico. Zaffaroni e Pierangeli (27).

Esse procedimento se difere da pena, pois, enquanto a pena tem caráter declaradamente punitivo, a medida de segurança tende a se apresentar de forma mais preventiva (20).

A longa permanência da loucura como perigo no imaginário social e na engrenagem penal faz com que não se questione com frequência se a internação asilar de fato se propõe a proporcionar melhora ao quadro de sofrimento do sujeito, pois o afastamento da convivência social já seria suficiente sob uma perspectiva de contenção de riscos.

\section{Do Risco ao Perigo e à Periculosidade}

Apesar da pluralidade de conceitos a respeito do entendimento do risco, existe um elemento transversal a todas as suas definições: a distinção entre possibilidade e realidade (28), ou seja, aquilo que é possível acontecer pode ou não transformar-se em realidade. Nesse sentido, fica evidente que a incerteza é uma das dimensões do risco. Ewald (28) afirma que o cálculo do risco desenvolve formas e métodos para transformar o imprevisível em previsível.

Nos Séculos XIX e XX foram desenvolvidas várias definições para a noção de periculosidade, sendo concebida geralmente como a probabilidade, e não a mera possibilidade de que uma pessoa venha a reincidir no crime, conforme Bourgeois e Bénézech (31).

Cohen (32) explica que "a periculosidade não está vinculada ao ato em si, mas sim à falta de compreensão do indivíduo que vai infringir uma proibição legal ou à sua 
incapacidade de determinar-se de acordo com esse entendimento". Esse entendimento faz com que seja possível não julgar exatamente 0 ato praticado, mas a personalidade da pessoa (33), pois o objetivo da intervenção penal para inimputáveis não é a punição de um crime cometido, mas a prevenção de crimes futuros. Assim, a periculosidade torna-se o fundamento do direito de prevenir, ainda que só possa ser enunciada depois de um primeiro crime.

A questão que emerge dessa análise é se é possível definir a medida de segurança como uma intervenção de saúde, mesmo que se baseie no conceito de periculosidade. Se o fundamento primordial da medida é garantir a segurança social, como indicado pelo próprio nome do instituto, que atenção à saúde é possível? Constata-se que a periculosidade criminal implica necessariamente um juízo de probabilidade de o sujeito vir a cometer novos delitos, mas nada diz sobre seu sofrimento mental ou necessidades de cuidado.

\section{A Criminalização da Doença Mental e a Patologização do Ato Delituoso}

O manicômio judiciário no Brasil passou a ser denominado Hospital de Custódia e Tratamento Psiquiátrico (HCTP) a partir da Reforma Penal de 1984, sendo que os Estabelecimentos de Custódia e Tratamento Psiquiátrico incluem não só os hospitais, mas também as Alas de Tratamento Psiquiátrico localizadas no interior de presídios ou penitenciárias.

De acordo com o Censo dos Estabelecimentos de Custódia e Tratamento Psiquiátrico (ECTPs), realizado no ano de 2011, o Brasil conta com 23 Hospitais de Custódia e Tratamento Psiquiátrico (HCTPs) e 3 Alas de Tratamento Psiquiátrico (ATPs), localizadas em complexos penitenciários (6).

Constatou-se que em 2011 a população total dos 26 ECTPS era formada por 3.989 indivíduos, dos quais 92\% (3.684) eram homens e 7\% (291) eram mulheres. A maioria era composta por sujeitos que já enfrentavam situação de vulnerabilidade dentro da sociedade. Nesse contexto, o Censo 2011 aponta que parte considerável dos internos é formada por pardos e pretos (44\%), que em geral possuem baixo nível de escolaridade, com 23\% de analfabetos e 43\% com nível fundamental incompleto. Havia também uma concentração de indivíduos que exerciam ocupações que exigem pouca ou nenhuma qualificação, e que correspondem a baixa remuneração, como vendedores em comércio e trabalhadors na área 
agropecuária (31\%) e trabalhadores industriais (22\%). Os desempregados constituíam 17\% da população (6).

\section{A População dos Estabelecimentos de Custódia e Tratamento Psiquiátrico (ECTPs)}

O Censo 2011 demonstra que dos 3.989 indivíduos, 2.839 estavam em medida de segurança, 117 estavam em medida de segurança por conversão de pena e 1.033 estavam em situação de internação temporária (Gráfico 1).

\section{Gráfico 1 - População Total de 3.989 individuos dos 26 ECTPs}

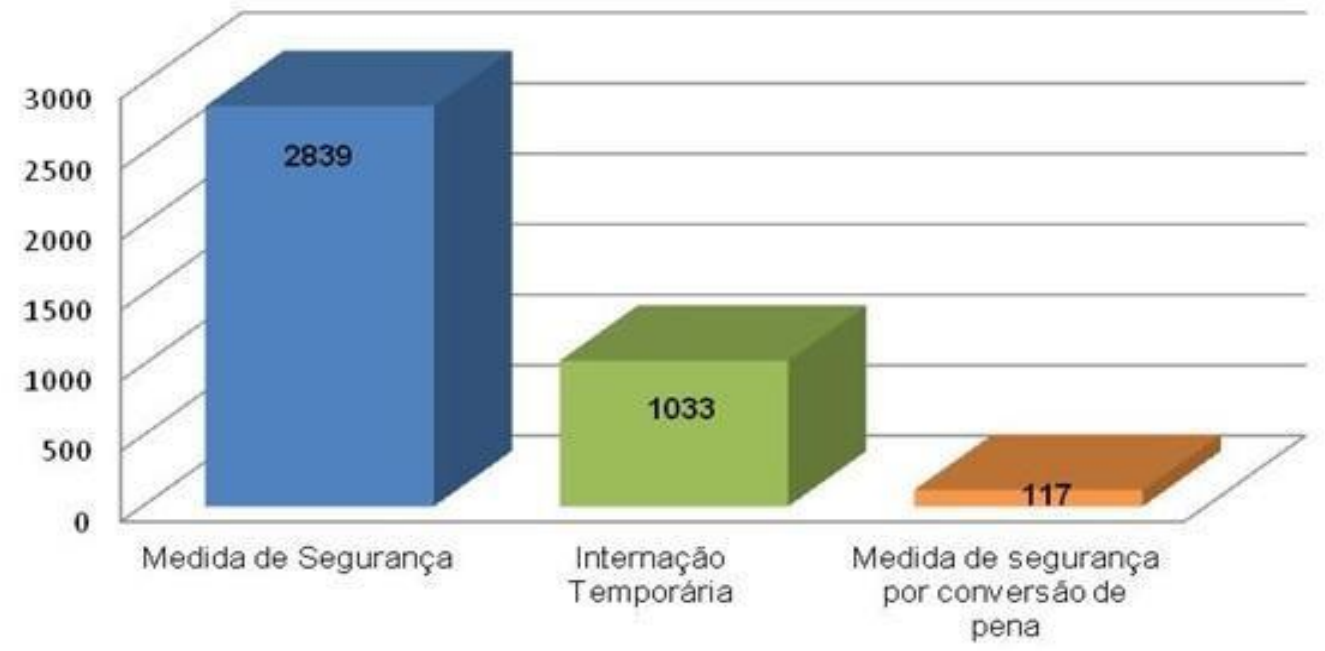

Fonte: A Custódia e o Tratamento Psiquiátrico no Brasil - Censo 2011

Dos 2.839 indivíduos em medida de segurança no Brasil cerca de 69\% (1.963) dos indivíduos não haviam cometido nenhuma infração penal anterior à que conduziu a atual medida de segurança, ou seja, antes de suas internações e, assim, poderiam ser considerados réus primários. A primariedade é um dos fatores que favorece a aplicação de medida alternativa à reclusão para os crimes de baixo potencial ofensivo no sistema penal comum, mas no caso de loucos infratores é ignorado. 


\section{Os Indivíduos em Internação Temporária}

Em situação temporária, dos 1.033 indivíduos, 34\% (353) estavam internados para realizar exame de sanidade mental, sendo que $27 \%$ (97) aguardavam dentro do prazo legal previsto pelo Código de Processo Penal, de 45 dias, e 69\% (244) aguardavam por um período superior a esse prazo (Gráfico 2).

Constata-se que não são garantidas as determinações legais devido à média de atraso para a realização desses exames ser em torno de 10 meses, quase sete vezes mais que o prazo definido como aceitável. Além disso, 35\% (362) dos indivíduos em internação temporária já tinham o laudo de sanidade mental, porém aguardavam decisão judicial para andamento processual (Gráfico 2).

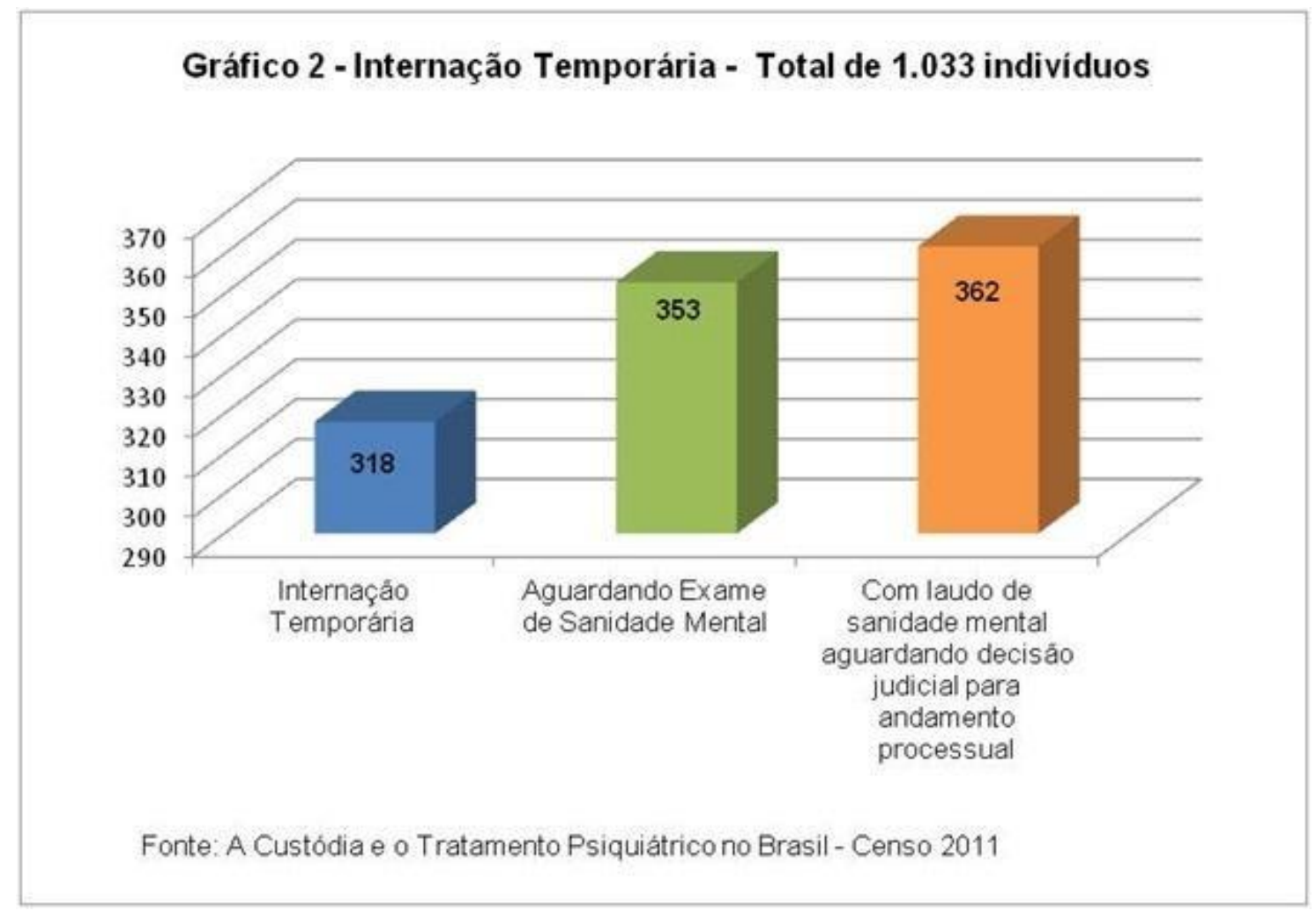

Observa-se que o indivíduo, mesmo sem ter a insanidade estabelecida, por estar aguardando a realização do exame de sanidade mental, deve ser encaminhado a uma instituição hospitalar, sem indicação médica e sem orientação para submissão a tratamento, mas por ter ordem estritamente judicial. Assim, são no mínimo 45 dias - e, na prática, muito 
mais que isso - em que esse indivíduo poderá ficar internado em um manicômio ou instituição similar, capaz de, por seus próprios mecanismos de isolamento social, alterar a conduta e a disposição psicoafetiva de qualquer indivíduo.

\section{O Período de Internação da População Temporária e a confirmação da apartação como defesa social}

População temporária é aquela que não recebeu sentença de medida de segurança, ou seja, que está internada sem determinação clara da justiça sobre a necessidade de estar lá. Vale destacar que entre a população temporária dos ECTPs 59\% (612) estavam internados havia menos de um ano, 31\% (324) estavam internados entre um e três anos, $3 \%$ (30) estavam internados entre quatro e cinco anos, 3\% (26) estavam internados entre seis e dez anos, 1\% (10) estava internado entre onze e quinze anos, 0,3\%

(3) estava internado entre dezesseis e vinte anos, um (1) único indivíduo estava internado entre 21 e 25 anos, e dois (2) indivíduos estavam internados havia mais de trinta anos (Gráfico 3).

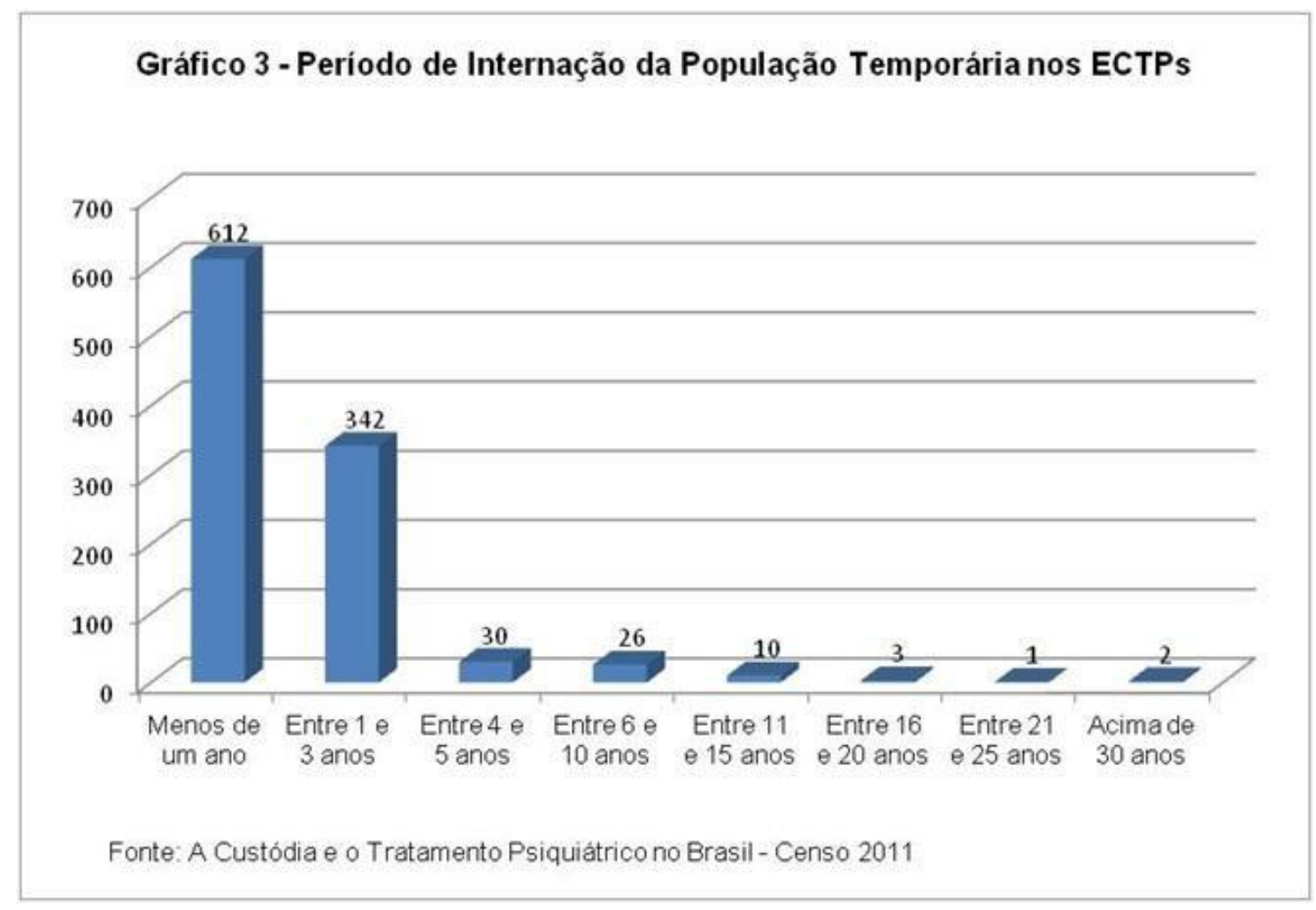


A porcentagem de indivíduos em internação temporária prolongada pode até ser vista como pequena em comparação com o total, mas evidencia a possibilidade de absurdo desse sistema: é possível que sujeitos sejam abandonados aos manicômios por décadas sem que haja resposta oficial do Estado sobre sua situação.

\section{Os Indivíduos em Medida de Segurança}

Os dados do Censo 2011 demonstram que pelo menos 25\% (741) dos indivíduos em medida de segurança não deveriam estar internados, por diversos motivos: já receberam laudo de cessação de periculosidade, sentença de desinternação, extinção de medida de segurança, alta médica ou desinternação progressiva da justiça, ou mesmo estão em internação sem processo judicial (Gráfico 4).

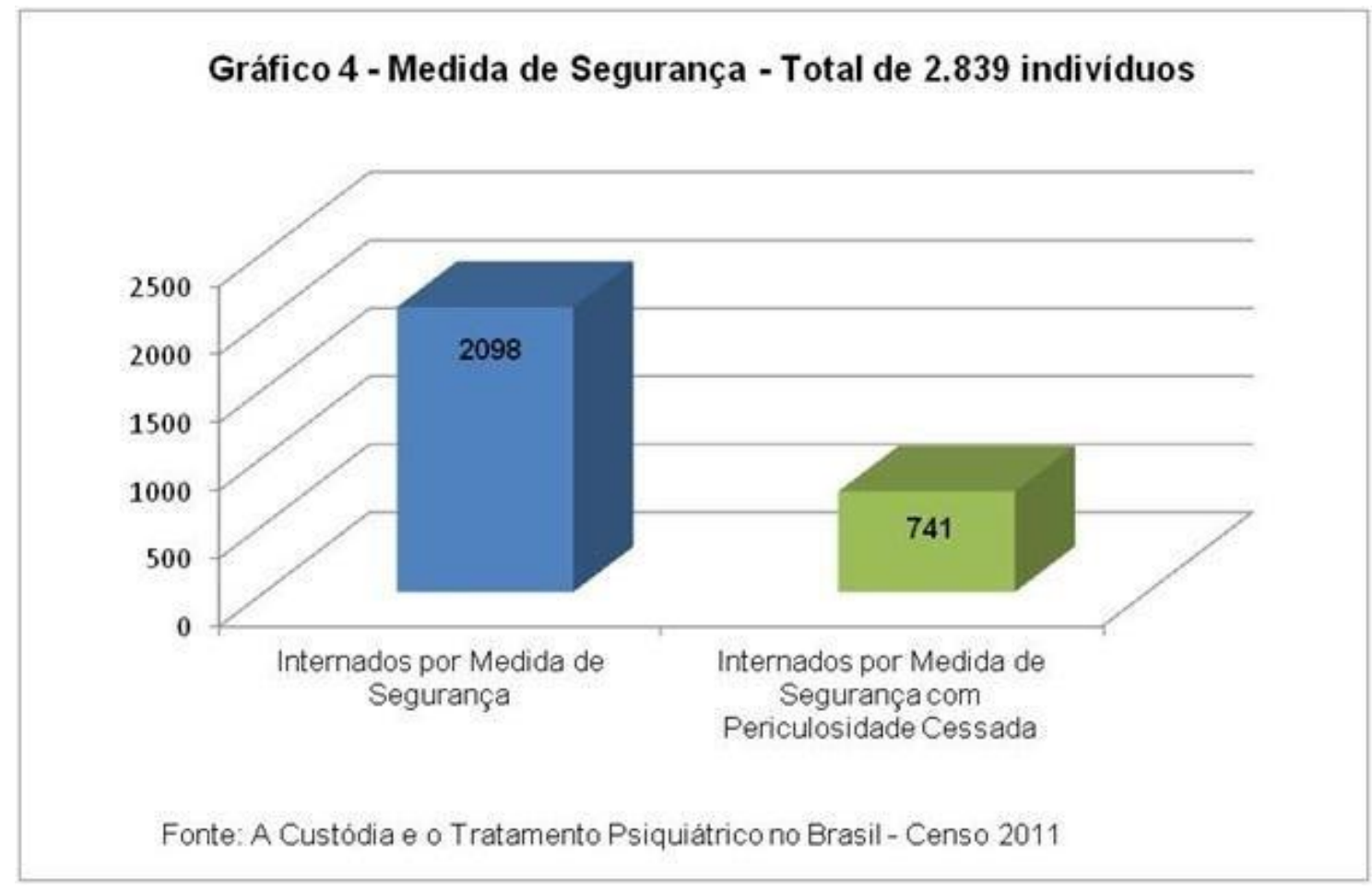

É importante esclarecer que após declarada a cessação da periculosidade, a pessoa internada em medida de segurança tem direito a receber a sentença de desinternação condicional, a qual tem o prazo de doze meses e, após esse período, caso não haja intercorrência que leve o indivíduo à reinternação em ECTPs, a medida de segurança 
é considerada extinta. Verificou-se que a saída dos manicômios tem sido negada a pelo menos 741 indivíduos que já obtiveram esse direito, o que representa um quarto da população total dos ECTPs.

Além disso, 41\% (1.153) desta população em medida de segurança estava em atraso com a realização anual do exame de cessação de periculosidade.

De acordo com Cintra Júnior (34), "a inimputabilidade acaba tendo, em razão da lei, um tratamento muito mais penal que terapêutico", pois a instância custodial acaba prevalecendo através da justificativa de medida de segurança social.

O Censo 2011 demonstra ainda que o segundo maior grupo populacional internado é de deficientes mentais (classificados pelo CID 10 como „retardo mental"), compondo 16\% da população total (6). A reclusão desses indivíduos fere diretamente a Convenção de Pessoas Portadoras de Deficiência das Nações Unidas, da qual o Brasil é signatário.

Para Queiroz (2010), respeitando a Lei ํㅜ 10.216/2001:

(...) independentemente da gravidade da infração penal cometida, preferir-se-á o tratamento menos lesivo à liberdade do paciente, razão pela qual, independentemente da pena cominada (se reclusão ou detenção), o tratamento ambulatorial (extra-hospitalar) passa a ser regra, e a internação, a exceção, apesar de o Código dispor em sentido diverso (36).

\section{O Período de Cumprimento da Medida de Segurança e a reafirmação do modelo hospitalocêntrico nos ECTPs}

O Censo 2011 demonstrou que, 56\% (1.648) das pessoas em medida de segurança estavam internadas há mais tempo do que a pena mínima que poderiam ter sofrido se não fossem considerados inimputáveis. Além disso, 21\% (606) das pessoas internadas cumpriam medida de segurança há mais tempo que a pena máxima em abstrato para a pena relativa ao ato infracional cometido.

A pesquisa do Censo 2011 identificou diversas situações alarmantes, dentre as quais dez dos casos mais graves. (Tabela 1). 
Cad. Ibero-Amer. Dir. Sanit., Brasília, v.4, n.3, jul./set. 2015 ISSN 2358-1824

Tabela 1 - População em medida de segurança internadas há mais tempo do que a pena mínima que poderiam ter sofrido se não fossem considerados inimputáveis

\begin{tabular}{cccc}
\hline Crime & Data da Sentença & Tempo da MS & Pena Máxima em Abstrato \\
\hline Tentativa de furto & $10 / 10 / 1979$ & 32 anos & 2 anos e 8 meses \\
\hline Homicídio culposo & $30 / 05 / 1979$ & 31 anos & 3 anos \\
\hline Lesão corporal & $10 / 01 / 1985$ & 26 anos & 1 ano \\
\hline Lesão corporal & $03 / 09 / 1985$ & 25 anos & 1 ano \\
\hline Incêndio culposo & $27 / 01 / 1986$ & 25 anos & 2 anos \\
\hline Lesão corporal & $27 / 05 / 1988$ & 23 anos & 1 ano \\
\hline Lesão corporal & $20 / 05 / 1988$ & 22 anos & 1 ano \\
\hline Homicídio culposo & $13 / 06 / 1986$ & 24 anos & 3 anos \\
\hline $\begin{array}{c}\text { Tentativa de estrupo e } \\
\text { violação de domicílio }\end{array}$ & $21 / 02 / 1983$ & 28 anos & 6 anos e 11 meses \\
\hline Homicidio culposo & $05 / 08 / 1987$ & 24 anos & 3 anos \\
\hline Fonte: A Custódia e o Tratamento Psiquiátrico no Brasil - Censo 2011 & \\
\hline
\end{tabular}

A periculosidade criminal que justifica essa permanência prolongada funda-se, portanto, na ideia de que o louco infrator, movido por certos apetites e impulsos que são próprios a seu transtorno mental, provavelmente praticará novos delitos, configurando-se a medida de segurança como a única modalidade sancionatória adequada para tratá-lo ou simplesmente neutralizá-lo (37).

Pode-se concluir que a medida de segurança se justifica por um dispositivo frágil do ponto de vista psiquiátrico e penal - a periculosidade do indivíduo -, que nada mais é do que um prognóstico impossível de ser provado, porque não apresenta elementos objetivos de identificação e quantificação. A utilização desse conceito indica uma clara tendência à adoção de um modelo punitivo voltado para a defesa social, no qual as penas tendem a se alongar na mesma medida em que os direitos dos apenados são restringidos, o que ocorre em detrimento da ressocialização do louco infrator e da atenção ao seu direito à saúde (41).

\section{Considerações Finais}

O paradigma psiquiátrico clássico, inaugurado com Phillipe Pinel, classificou o portador de sofrimento mental como um sujeito que traz em si um déficit moral intrínseco, portador de um mal moral, e assim proporcionou a renovação do conceito de alienação mental. 
A medicina e o saber-poder psiquiátrico continuam ao longo da história recente com a capacidade de definir e decidir sobre o que é o normal, o anormal e o patológico, como também exercer o poder normalizador sobre essas subjetividades. A perícia médica, e mais especificamente a psiquiatria forense, é a área que dispõe da função de constatar a insanidade mental, a periculosidade do indivíduo e a cessação da periculosidade do sujeito.

A ideia pineliana de um déficit moral intrínseco na loucura, que faz dos loucos indivíduos intrinsecamente perigosos, é algo que se arrasta imutavelmente em todas as teses sobre a periculosidade e permanece até os dias de hoje.

Os Estabelecimentos de Custódia e Tratamento Psiquiátrico (ECTPs) integram o sistema penitenciário e, consequentemente, seguem as determinações da Lei de Execução Penal, com isso, acabam mantendo um modelo desvinculado de um sistema integrado de atenção em saúde mental, assim, confirmando a ideia de que a medida de segurança se identifica mais com a pena do que com um instrumento terapêutico.

A Lei de Reforma Psiquiátrica trouxe um modelo substitutivo de saúde mental que se constitui em importante passo no sentido de resgatar a cidadania do portador de sofrimento psíquico. A promulgação dessa Lei, no entanto, não provocou nenhuma alteração significativa na sistemática de aplicação das medidas de segurança.

A presunção da periculosidade intrínseca à loucura é o que permite a permanência desse regime de saber-poder que encarcera os chamados inimputáveis com base no medo social, e não thes garante o devido acesso à saúde.

Assim, resta claro que o modelo manicomial, baseado em uma legislação penal que identifica na loucura uma possibilidade de perigo, precisa ser repensado para que se garanta verdadeira atenção em saúde ao louco infrator. Por fim, importante destacar que o resgate da cidadania dessas pessoas portadoras de sofrimento mental em conflito com a lei não se exaure com a extinção pura e simples dos Estabelecimentos de Custódia e Tratamento Psiquiátrico, pois é necessário que se discuta e se exija a implementação de políticas de saúde mental voltadas a afirmar a atual legislação. 


\section{Referências Bibliográficas}

1 Castro UR de. Reforma psiquiátrica e o louco infrator: novas ideias, velhas práticas. Brasília: Hinterlândia; 2009.

2 Carrara S. Crime e loucura: o aparecimento do manicômio judiciário na passagem do século. Rio de Janeiro: EdUERJ; 1998.

3 Corrêa JM. O doente mental e o direito. São Paulo: Iglu; 1999.

4 Costa ACF. Direito, saúde mental e reforma psiquiátrica. In: Márcio lorio Aranha, organizador. Direito sanitário e saúde pública, Brasília: Ministério da Saúde; 2003.

[Internet]. Brasília, 2003. [Acesso em 10 out 2014]. Disponível

em http://bvsms.saude.gov.br/bvs/publicacoes/direito san v1.pdf..

5 Foucault M. História da loucura na idade clássica. São Paulo: Perspectiva; 2004a.

6 Diniz DA. Custódia e o Tratamento Psiquiátrico no Brasil - Censo 2011. Brasília: Letras Livres; 2013. [Acesso em 10 out 2014]. Disponível em:

http://newpsi.bvspsi.org.br/ebooks2010/pt/Acervo files/custodia tratamento psiquiatrico $\mathrm{n}$ o brasil censo2011.pdf.

7 Gil AC. Métodos e técnicas de pesquisa social. São Paulo: Atlas; 2007.

8 Brasil. Lei no 10.216, de 6 de abril de 2001. Dispõe sobre a proteção e os direitos das pessoas portadoras de transtornos mentais e redireciona o modelo assistencial em saúde mental. [Internet]. Brasília, 6 abr 2001. [Acesso em 10 out 2014]. Disponível em www.planalto.gov.br/ccivil 03/Leis/LEIS 2001/L10216.htm.

9 Minayo MC de S. O desafio do conhecimento: pesquisa qualitativa em saúde. São Paulo: Hucitec; 2006.

10 Pelbart PP. Da clausura do fora ao fora da clausura - loucura e desrazão. São Paulo: Brasiliense; 1989.

11 Machado R et al. Danação da norma: a medicina social e constituição da psiquiatria no Brasil. [Internet]. Rio de Janeiro: Edições Graal; 1978. [Acesso em 10 out 2014] .Disponível e:

http://minhateca.com.br/niltonvarela/Documentos/Ebooks/Hist* ${ }^{*}{ }^{*}$ b3ria++Teoria+e+Historio grafia/MACHADO*2c+Roberto.+Dana ${ }^{*}{ }^{*}{ }^{*} a 7^{*}{ }^{*} 3^{*} a 30+d a+$ norma++medicina+social+e+cons titui ${ }^{*}{ }^{*}{ }^{*} a 7^{*} \mathrm{c} 3^{*} a 30+d a+$ psiquiatria+no+Brasil,1325198.pdf.

12 Silveira LC, BRAGA VAB. Acerca do conceito de loucura e seus reflexos na assistência de saúde mental. Revista Latino-Americana de Enfermagem [Internet]. 2005 [Acesso em 10 out 2014], 13(4): 591-595. Disponível em http://www.scielo.br/pdf/rlae/v13n4/v13n4a19.pdf.

13 Barros-Brisset FO de. Genealogia do conceito de periculosidade. Responsabilidades [Internet]. 2011 [Acesso em 10 out 2014], 1(1): 37-52. Disponível em 
http://www8.tjmg.jus.br/presidencia/programanovosrumos/pai pj/revista/edicao 01 1/02GENEALOGIA\%20DO\%20CONCEITO\%20DE\%20PERICULOSIDADE.pdf.

14 Goffman E. Manicômios, Prisões e Conventos. São Paulo: Perspectiva; 2003.

15 Foucault M. Microfísica do Poder. São Paulo: Graal; 2004b.

16 Resende H. Política de saúde mental no Brasil: uma visão histórica. Cidadania e loucura: políticas de saúde mental no Brasil. Petrópolis: Vozes, co-edição ABRASCO; 2001.

17 Foucault M. O poder psiquiátrico. São Paulo: Martins Fontes; 2006.

18 Amarante PD de C. Loucos pela vida: a trajetória da reforma psiquiátrica no Brasil. Rio de Janeiro: FIOCRUZ; 1998.

19 D'incao MA. Sociabilidade e doença mental. Doença mental e sociedade: uma discussão interdisciplinar. Rio de Janeiro: Graal; 1992.

20 Correia LC, LIMA IMSO, Alves VS. Direitos das pessoas com transtorno mental autoras de delitos. Cadernos de Saúde Pública [Internet]. 2007 [Acesso em 10 out 2014], 23(9): 1995-2012. Disponível em http://www.scielo.br/pdf/csp/v23n9/02.pdf.

21 Brasil. Decreto oㅜ 1.132, de 22 de dezembro de 1903. Reorganiza a assistência a alienados. In: Collecção de Leis da República dos Estados Unidos do Brasil de 1903 Actos do Poder Legislativo. Rio de Janeiro: Imprensa Nacional, 1903.[Internet]. Brasília. [Acesso em 10 out 2014]. Disponível em: http://www2.camara.leg.br/legin/fed/decret/19001909/decreto-1132-22-dezembro-1903-585004-publicacaooriginal-107902-pl.html.

22 Musse, L. B. Políticas Públicas em Saúde Mental do Brasil na perspectiva do Biodireito: as experiências dos estados de Minas Gerais e São Paulo sob a égide da Lei no 10.216/2001 e suas implicações. [Tese] [Internet]. São Paulo: Programa de Doutorado em Filosofia do Direito e Estado, Pontifícia Universidade Católica de São Paulo; 2006. [Acesso em 10 out 2014]. Disponível em: http://www.dominiopublico.gov.br/download/teste/arqs/cp011773.pdf.

23 Barros DD. Cidadania versus periculosidade social: a desinstitucionalização como construção do saber. Psiquiatria Social e Reforma Psiquiátrica [Internet]. 1994ª [Acesso em 10 out 2014], 171-195. Disponível em

http://www.scielo.br/scielo.php?script=sci $\quad$ nlinks\&ref=000086\&pid $=\$ 1413294 X 2004000200$ 02000001\&lng=en.

24 Marques JF. Tratado de Direito Penal. VIII. São Paulo: Millenium Editora; 2000.

25 Prado LR. Curso de direito penal brasileiro, v. 1: parte geral, arts. $1^{\circ}$ a 120. São Paulo: Revista dos Tribunais; 2011.

26 Lebre, M. Medidas de segurança e periculosidade criminal: medo de quem? Responsabilidades [Internet]. 2013 [Acesso em 10 out 2014], 2(2): 273-282. Disponível em 
http://www8.tjmg.jus.br/presidencia/programanovosrumos/pai pj/revista/edicao 02 02/06 ResponsabilidadesV2N2 Norte02.pdf.

27 Zaffaroni ER, Pierangeli JH. Manual de Direito Penal brasileiro: parte geral. São Paulo: Revista dos Tribunais; 2004.

28 Areosa J. O risco no âmbito da teoria social. In: VI Congresso Português de Sociologia, 2008 [Internet]. Lisboa: Mundos Sociais: Saberes e Práticas, 2008, 323. [Acesso em 10 out 2014]. Disponível em http://www.aps.pt/vicongresso/pdfs/323.pdf.

29 Palomba G. Tratado de Psiquiatria Forense Civil e Penal. São Paulo: Atheneu; 2003.

30 Mayrink da Costa, Direito Penal. São Paulo: Forense, 2008

31 Almeida FM de. Fronteiras da Sanidade: Da „Periculosidade" ao „Risco" na articulação dos discursos psiquiátricos forense e jurídico no Instituto Psiquiátrico Forense Maurício Cardoso de 1925 a 2003 [Teste] [Internet]. Porto Alegre: Universidade Federal do Rio Grande do Sul; 2009. [Acesso em 10 out 2014]. Disponível em: https://www.lume.ufrgs.br/bitstream/handle/10183/18411/000727172.pdf?sequence=1 .

32 Cohen C. Medida de segurança. Saúde mental, crime e justiça. São Paulo: EDUSP; 2006a.

33 Quinet A. Crime e responsabilidade. Psicanálise e Psiquiatria: controvérsias e convergências. Rio de Janeiro: Rios Ambicioso; 2001.

34 Cintra Júnior DAD. Direitos humanos e saúde mental. Escritos em homenagem a Alberto Silva Franco. São Paulo: Revista dos Tribunais; 2003:151-162.

35 Brasil. Decreto ํㅜ 6.949, de 25 de agosto de 2009. Promulga a Convenção Internacional sobre os Direitos das Pessoas com Deficiência e seu Protocolo Facultativo, assinados em Nova York, em 30 de março de 2007. [Internet]. Brasília. [Acesso em 10 out 2014]. Disponível em: http://www.planalto.gov.br/ccivil 03/ ato20072010/2009/decreto/d6949.htm.

36 Queiroz P. Curso de Direito Penal: Parte Geral. Rio de Janeiro: Juspodivm; 2010.

37 Lebre, M. A Inconstitucionalidade da Medida de Segurança face a Periculosidade Criminal. [Dissertação] [Internet]. Curitiba: Programa de Mestrado das Faculdades Integradas do Brasil (UniBrasil); 2009. [Acesso em 10 out 2014]. Disponível em: http://www.facbrasil.edu.br/sitemestrado/ pdf/marcelo lebre.pdf.

38 Rauter C. Criminologia e Subjetividade no Brasil. Rio de Janeiro: ICCrim;2003.

39 Barros DM de, Teixeira EH. Manual de Perícias Psiquiátricas. São Paulo: Artmed; 2015.

40 Hungria, N. Dotti,RA. Comentários ao Código Penal. São Paulo: GZ Editora,1984 
41 Santos NAG. Do hospício à comunidade: políticas públicas de saúde mental. [Internet]. Florianópolis: Letras Contemporâneas; 1994. [Acesso 10 out 2014]. Disponível em: https://repositorio.ufsc.br/handle/123456789/111916.

42 Bastos CL. Opinião. Psychiatry On-line Brazil, [Internet]. 2007 [Acesso em 10 out 2014], 12(10). Disponível em: http://www.polbr.med.br/ano07/lbp1007.php.

43 Peres MFT, Nery Filho A. A doença mental no direito penal brasileiro: inimputabilidade, irresponsabilidade, periculosidade e medida de segurança. História, Ciências, Saúde. [Internet]. 2002 [Acesso em 10 out 2014], 9(2): 335-55. Disponível em http://www.scielo.br/pdf/hcsm/v9n2/a06v9n2.pdf.

Recebido para publicação em 30 de janeiro de 2015. Admitido para publicação em 02 de julho de 2015. 